\title{
FUNDAMENTOS FILOSÓFICO-ANTROPOLÓGICOS DE LA FIDELIDAD Y EL COMPROMISO*
}

\section{DOI: https://doi.org/10.52039/seminarios.v52i179.675}

Autor: Miguel García Baró. Profesor en la Universidad Pontificia de Comillas, Madrid.

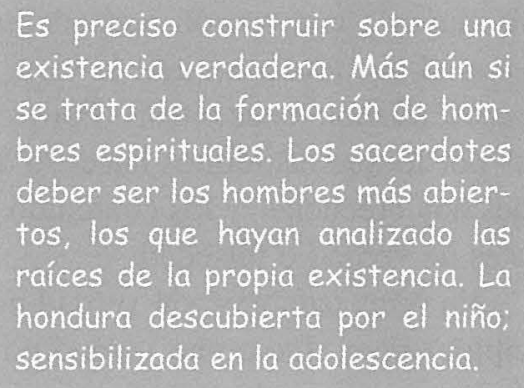

Es preciso construir sobre una existencia verdadera. Más aún si se trata de la formación de hom bres espinituales. Los sacerdotes deber ser los hombres más abiertos, los que hayan analizado las raices de la propia existencia. La sensibilizada en la adolescencia. 
cotidiana. Ya Sócrates, el primer pensador existencialista, decía que el hombre no puede vivir una vida sin examen: no que no le sea digna una vida así, sino que no le es posible.

Nos estamos acostumbrando de mil maneras a desoír este imperativo universal y categórico, pero urge que despertemos de nuevo plenamente a su verdad. Y es que la existencia humana está tejida de acciones, que siempre vienen a ser (esta enseñanza procede de Kant) consecuencias de opciones generales, las cuales, a su vez, derivan de actitudes globales ante sectores de la vida y, finalmente, de un modo básico de hallarse el hombre instalado en ésta. En todos estos niveles -he diferenciado sólo cuatro para simplificar, pero en concreto seguramente se nos ofrecerían en número mayor-, una opción o el adoptar una actitud, una acción o la postura general que tomamos ante la vida, son, además de acontecimientos y procesos, afirmaciones o tesis. Porque creemos determinada presunta verdad es por lo que decidimos hacer lo que hacemos. En el fondo de las actitudes hay creencias, y los contenidos de las creencias son siempre susceptibles de verdad o falsedad.

En otras palabras: sin verdad no hay existencia humana, pero, en principio, tomar algo como verdad no se hace porque se haya analizado cuidadosa y personalmente una tesis y se haya encontrado que, en efecto, es verdadera o, al menos, muy probable. La lastimosa condición del hombre como sujeto teórico, que expresa algo tan parecido a la consecuencia del pecado original como para que Heidegger, por ejemplo, la denomine caída en lo impropio, es que no somos personal y responsablemente nosotros, de manera activa, reflexiva y libre, quienes pasamos a creer lo que merece la pena ser creído, sino que la mayor parte de este trabajo teórico fundamental se nos da hecho y nos lo tragamos, por decirlo con una metáfora socrática, todo él ya preparado y hasta masticado. Más que creer yo mismo aquello que se ha convertido palpablemente en el suelo de verdad de mi existencia acto por acto, actitud por actitud, hábito por hábito, me lo han dado ya creído. Creo como creo porque se cree así en la comunidad en la que me muevo. Y de hecho los conflictos y crisis no proceden muchas veces de que alguien empiece, como el individuo que es y que debería comenzar de una vez a ser, a realizar la criba de las verdades recibidas, sino que tienen más bien su origen en que, como es propio de sociedades desestructuradas, nos movemos al mismo tiempo entre más de un círculo de creencias, y lo que aceptamos en un sitio no nos da el pase para 
otro que también nos interesa. Y así, o tenemos mil caras, según dónde nos encontremos en cada hora, o caemos en depresiones y enfermedades del alma, porque nuestra guarida de creencias se descompone en cuanto le da un soplo de aire extranjero.

Pero sigue siendo inconmovible verdad acerca del hombre que hace éste lo que hace porque cree lo que cree; y como sólo las acciones, las opciones, los hábitos y las actitudes nos acercan o nos alejan de la plenitud posible de nuestra existencia, depende ésta de la solidez de las verdades sobre las que está toda construida. Con un matiz elemental: que nadie puede hacer por cada uno de nosotros el trabajo doble e ímprobo de, primero, sacar a luz, en un esfuerzo de ironía, cuáles son las auténticas creencias que forman el suelo de la existencia personal; y segundo, en un esfuerzo de partera de sí mismo, hacer lo que san Ignacio llama la probación de sí, o sea, de nuestras personales reales creencias. No tenemos un Sócrates a nuestro lado todo el tiempo, ni lo necesitamos; pero entre las cosas que creemos a pies juntillas está también la de que por nosotros solos somos incapaces de estos esfuerzos -si es que no nos detenemos mucho antes con alguna de esas frases hechas sobre si tiene o no doctores la Santa Madre Iglesia, o sobre si pensar es aburrido y no sirve para nada o hasta es contraproducente, da jaqueca y nos vuelve locos-.

La impresionante situación de nuestro mundo se ilumina mejor que de otros modos cuando recapacitamos en que estoy hablando de un evidente deber universal, que no podemos negar con sólo que reflexionemos dos minutos acerca de él, pero que se trata hoy de un secreto guardado bajo siete veces siete llaves. Una sociedad de la información, dominada hasta la tiranía por las técnicas de esa dudosa ciencia que es la pedagogía, es hoy al mismo tiempo la sociedad que más profundamente ha decidido ignorar el universal deber de socratismo, si me permitís decirlo así, que afecta a la vida humana. Es imprescindible la filosofía para poder vivir vida humana -0 , si remontamos el concepto, vida espiritual de alguna clase y calidad-, pero nadie lo dice y, por consiguiente, a casi nadie se le ocurre que sea cierto. La búsqueda personal, responsable, radical de la verdad, como requisito primero de la vida, no tiene casi ningún propagandista, pero es un deber evidente, una condición necesaria de la dicha, un prerrequisito de la misma salvación, entendida en términos propiamente religiosos; y así figura en todos los grandes clásicos no fideístas, o sea, no heterodoxos, de nuestra tradición espiritual. 
Ya en toda formación humana, aunque esté destinada a lograr buenos técnicos en las materias aparentemente más ajenas a lo directa y centralmente humano, el problema de la verdad existencial debería estar afrontado, so pena de que un economista, un ingeniero, un médico corran el riesgo de ignorar por completo qué hacer con la vida suya y con las vidas de los demás y con la naturaleza que manejan a cada paso; pero esta evidencia crece hasta lo que no se puede exagerar cuando nos referimos a la formación de hombres espirituales, de gentes destinadas a vivir siempre en la cercanía de lo sacramental y a inducir la relación con lo sagrado en su grupo social. Exactamente en los antípodas de cualquier veleidad que conduzca a formar a estas personas como en un invernadero social, el primer deber pedagógico para con ellos es exponerlos en la mayor medida posible al fuerte viento de la verdad, a la realidad histórica en todas sus facetas y toda su crudeza, y, desde luego, procurar que se abran a todas las posibilidades existenciales que corresponden al mundo en que han nacido. Los que se vean llamados de una manera especial a vivir en la intimidad del misterio divino y en la comunidad de los ordenados de la Iglesia, deben ser los hombres más abiertos, más probados, más expuestos a la realidad y que más hayan analizado las raíces de su propia existencia. Insisto en que hasta aquí -como ocurrirá también en los próximos minutos- sólo estoy hablando de temas antropológicos de relevancia universal; pero en el caso de las personas que toman sobre ellas la responsabilidad mayúscula del sacerdocio, si es que cabe subrayar y exaltar lo que de suyo es de índole general, no hay duda de que esos subrayados y esas exaltaciones se aplican aquí mejor que en cualquier otro lado.

Pero ¿por qué es tan urgente, tan inevitable, tan fecundo espiritualmente, el viaje personal, radical, infinitamente libre, hacia las fuentes de la verdad? Consideremos que no se ha pretendido que hallarlas y exprimirlas sea un deber, sino que lo es vivir de camino, de aventura apasionada hacia ellas, en la esperanza de que se puede encontrar su rastro, su rumor e incluso su agua, aunque quizá no logremos beberla directamente del manantial. ¿No hay una sabia tradición que suple a nuestra debilidad personal? ¿No hay un primario deber de confianza en la tradición, que además es muy característico de la Iglesia Católica? ¿No empieza la vida espiritual por la recepción confiada y humilde de muchas verdades?

Estas preguntas me hacen pasar al punto segundo de nuestra común indagación en los fundamentos de la antropología. 


\section{$\S 2$ Superficie y profundidad existenciales}

La vida humana se vive normalmente en un estado de profunda división, y sobre este estar escindida nuestra vida en su intimidad tenemos todos alguna medida de conciencia, que solemos no exacerbar, como si temiéramos las consecuencias de hacerlo.

Esta duplicidad de planos entre los que transcurre nuestra vida cotidiana podemos analizarla llamando a uno de ellos superficial y a otro, profundo.

Hay pensadores pesimistas que achacan al hombre vivir tan sólo en la superficie de la existencia, y califican una actitud así como la natural. Otros, sólo un punto menos pesimistas que éstos, tienen conciencia de haber vivido muchos años en la mera superficialidad, hasta que los despertó con una tremenda sacudida la providencia amorosa de Dios proporcionándoles una tempestad existencial $\mathrm{o}$, dicho menos metafóricamente, una situación límite, que ellos, por la gracia de Dios, supieron reconocer como tal y lograron aprovechar para cambiar por entero de actitud.

Yo aún soy menos pesimista que los Pascal y Agustín, para no hablar del casi nihilismo de un Heidegger; y creo que las situaciones límites no son tanto como necesarias para la conversión de la actitud, debido a dos buenas razones. La primera es que siempre, por superficialmente que vivamos, nos queda otra, como le gustaba decir con socarronería popular a Unamuno; la segunda es que aquello que más merecería el nombre de situación límite nos ha sucedido a todos ya, de alguna manera, en los territorios medio olvidados de la infancia, y sus secuelas han resultado imborrables (de aquí que siempre nos quede otra). En la vida de adultos, cabe que un esfuerzo de lucidez como el socrático, o un empeño por ser fieles a las evidencias de orden moral, como el que sacude a tantas personas de nuestro tiempo que se atreven a ponerse en contacto directo con la inmensa miseria que hoy existe en casi todos los lugares; digo que cabe que, en la madurez de la vida, uno cualquiera de estos intentos por ser lúcido, auténtico y fiel al bien, lleven a una persona a los niveles, ya siempre presentes, de la existencia profunda, y de tal modo que, en adelante, aunque comprenda lo que sigue ocurriendo en la superficie de la vida, ya no quepa decir del todo que esta persona vive escindida, sino que es más justo considerar que se ha trasladado esencialmente al nivel de lo profundo y ha destruido, quizá enteramente, los puentes con lo superficial y las estructuras que la vieja superficialidad había levantado. 
El testimonio de muchos grandes pensadores y sentidores ha ido en la dirección de reconocer una conversión completa, una auténtica revolución en sus vidas, que antes eran, como dice insuperablemente Agustín, más muerte que vida, y ahora ya son de verdad vida abierta a la vida totalmente viva de la eternidad. Han viajado de la regio dissimilitudinis al lugar donde brillan los símbolos de lo divino. Pero me pregunto si no exageran, con estupendos fines pedagógicos, por otra parte, la novedad de lo que han descubierto después de convertirse y, por ello mismo, lo trágico y lo duro del giro que ha dado su vida, en esta colaboración entre la providencia y ellos mismos, entre la gracia y la libertad. Porque no es sólo mi memoria personal, o sea, un suceso de mi propia vida que podría entenderse como una contingencia, sino la memoria colectiva de todas las culturas la que testimonia a favor de que el niño es quien descubre como tales, un buen día (un dies irae que termina por ser la bendita herida inolvidable, tal como la cojera de Jacob después de luchar con el representante del Dios invisible), la presencia de la muerte, la posibilidad de lo divino, la diferencia entre las apariencias y la verdad, la seriedad del tiempo, lo irreversible de las decisiones y los acontecimientos; en definitiva: la hondura misteriosa de la existencia. Entonces mismo, la sociedad se apresura a cubrir lo que parece que ella siempre siente como un vacío peligroso: las preguntas innumerables, la gran pregunta total en la que se ha convertido la infancia, son sobreabundantemente respondidas por los sabios de la comunidad, y llegan al mismo tiempo las informaciones sobre los mitos fundacionales, las noticias acerca del nombre verdadero de los dioses, el cambio definitivo del propio nombre, las tareas de la madurez. Al personalísimo y solitario rito de paso lo acompaña la algarabía del rito de paso oficial, y el niño que acaba de dejar de serlo se ve excesivamente rico de respuestas, portador de tradiciones de secular sabiduría, que tratan de apagar su sed de verdad buscada a solas, y que pueden contribuir, por desdicha, a insertarlo de por vida y excesivamente en el impersonal se que, como decía malévola pero acertadamente Heidegger, siendo todos y nadie, es quien de verdad vive la vida de cada uno, reducido el pobre cada uno a no ser más que eso: uno, un número en la colectividad, uno en la masa de la gente.

Se pasa de la infancia a la adolescencia en esa noche del espíritu (para muchos niños, como se ha atrevido, por ejemplo, a testimoniar en primera persona Levinas, es realmente una o una serie terrible de noches recurren- 
tes) en la que, sin que se estuviera preparado para tal acontecimiento -lo más, se vivía en la angustia, según Kierkegaard, de que un día nos pasara empezar a vivir la incomprensible vida de los adultos, dejar de jugar...-, de pronto y de improviso, exactamente como una herida, entramos en el tiempo irreversible, comprendemos que todo pasa para no volver, empezamos a existir en la certeza de la muerte propia y de las muertes de todos los que nos rodean y queremos o tememos, y, por ello mismo, caemos en la cuenta de la verdad, del dolor, de la pregunta, del interés, de la pasión.

Es ésta la experiencia madre de todas las demás experiencias que haremos en adelante; es el segundo y más verdadero nacimiento, porque nos deja marcados a fuego y nos introduce en las primeras opciones, los primeros verdaderos amores, la posibilidad de las primeras profundas traiciones y maldades, de los primeros experimentos con la crueldad, el horror y el placer.

El niño no tiene conceptos para asimilar todo lo que se le viene encima, aparte de que se descubre enormemente solo con su pregunta terrible, en medio de gentes, en la familia, en la escuela, en la calle, que hablan de cualquier cosa menos de lo único importante; que se siguen empeñando en hacerle aprender infinidad de asuntos que ni le van ni le vienen; que viven como si fueran ahora todos los demás los que juegan, mientras que él, si sigue jugando, lo hace con un sentido nuevo, lleno de melancolía y de interés. El niño sólo tiene a su disposición los sentimientos y el silencio, y para los primeros es muy importante que pueda no faltarle música, poesía, arte de cualquier forma que sea. Es decisivo que comprenda que su estado lo han vivido, con la misma hondura que él lo tiene ahora que vivir, muchos otros hombres antes, de modo que se anime a ser fiel a las duras enseñanzas que está recibiendo a solas (quizá, en la compañía de los paisajes y los animales, o sea, de todo aquello que no corre, con el tiempo, a la muerte, o que no habla pero mira y siente).

Dice Franz Rosenzweig con muchísima razón que el niño que así es enseñado por la vida en la lección fundamental resulta más sabio que el adulto que, al volver a un estado semejante, piensa en el suicidio y hasta lo comete; porque un niño, lejos de suicidarse, aunque vive la apretura más terrible, la congoja más fuerte que quizá experimente en todos los días de su existencia, resuelve que esperará a vivir, como si conociera esta verdad esencial: que la acción puede añadir comprensión, mientras que ciertas paradas que intentan ser paréntesis de reflexión filosófica para que 
ahora o nunca, esta misma noche, se descubra la verdad esperanzadora, porque no se puede seguir viviendo con tanta carga, son ineficaces, engañosas, mucho menos sabias, aparte de mucho más peligrosas.

Hay que tener la fortuna de encontrar medios alrededor que ayuden a descubrir que si, desde luego, uno no tiene idea de qué es vivir y de qué es morir, vale la pena, absoluta, incondicionalmente, vivir para ver si el enigma se va desentrañando; que es infinitamente interesante vivir para buscar la verdad, y que esto implica no dejar sabiduría posible sin consultar, lengua sin conocer, país sin visitar, piedra que no vayamos a remover por ver si debajo no hay una gota de claridad.

Quiero subrayar muy expresamente un aspecto de la situación crucial de esta edad en la que se acaba de entrar en la existencia propiamente dicha: el descubrimiento de que la ignorancia en que se está acerca de la misma existencia y acerca de la dicha, es más profunda y tensa de lo que suele creerse luego. Porque descubrir la realidad cierta de la muerte supone en seguida enfrentarse al dilema tremendo de comprender que no deseamos ni podemos desear quedar muertos para siempre, pero que tampoco nos cabe desear lo que, en principio, se aparece como única alternativa: seguir vivos para siempre. No sabemos qué anhelamos; no sabemos en realidad y con plenitud cuál podría ser la figura de una existencia que colmara las medidas de nuestra dicha. No sabemos, pues, qué es exactamente ser, vivir, existir.

La situación de las profundidades siempre es enigmática, apasionante, aventurera, como una apuesta, según el célebre texto pascaliano. Es, por todo esto mismo, una invitación inolvidable a la lucidez, a la reflexión, a la acción. Deseamos morir y resucitar a una vida cuya índole desconocemos por completo: resucitar dentro de la resurrección, por decirlo de alguna manera, para que no nos canse la vida cuya condición temporal ha de ser absolutamente diferente de la que tan bien conocemos ahora. Pero no poseemos ninguna representación, ni imaginativa ni conceptual, de un tiempo que no sea como es este tiempo de ahora en el mundo.

\section{$\S 3$ El centro del alma y la esperanza absoluta}

La lección principal que este lado de la experiencia matriz nos enseña es que el objeto de nuestra esperanza se encuentra más allá de cualquier 
expectativa que caiga dentro del horizonte del mundo, dentro del horizonte de esta vida. Esperamos lo imposible, si es que el concepto de posibilidad se mide por los parámetros de lo mundano. Esperamos, necesitamos, no menos que el ciervo que va muerto de sed por un desierto, lo que los ojos no han visto aún en parte alguna, ni han tocado manos humanas, ni han escuchado nuestros oídos: lo que supera, incluso, aquello que se dibuja como objeto cierto del anhelo más puro e intenso que haya albergado jamás un corazón de hombre. Estamos hechos con una temible y magnífica capacitas Dei, que nos llena de inquieta tensión, mientras no se nos conceda la sobreabundancia del don imposible. Pero en tanto vivamos en las condiciones del mundo, permaneceremos en la inestabilidad de la apuesta, de la búsqueda apasionada, del deseo insensato, de la generosidad extrema respecto de todo lo que hayamos ido reuniendo, que siempre será tan ridículamente insuficiente para el viaje en el que se nos ha introducido sin pedirnos antes opinión.

La perspectiva de esta profundidad tan necesitada de razón, de acción y de pasión es lo que confiere a la vida de un hombre no sólo esperanza que se atreve a llamarse absoluta, sino también confianza y amor, o sea, fortaleza, justicia y misericordia en tales cantidades y de tal calidad que no sea disparate denominarlas virtudes teologales.

Lo mejor de la fenomenología contemporánea de la religión se refiere a la centralidad de una así llamada experiencia inobjetiva del Misterio divino; y esto mismo dice la lectura de lo que se descubre en el que Unamuno describía como el hondón del alma. No es el poder de la realidad en torno quien me enseña el significado del término Dios -significado que trae consigo la existencia de su objeto, como sostenía san Anselmo, aunque sea por un camino que quizá no coincida con la principal vía que este gran pensador propuso-. Aprendo esta palabra capital de todo vocabulario humano al tomar conciencia de la tensión irreductible que anima desde su centro mismo mi existencia: que es mi maestro interior constante, yo más yo que yo mismo, vitalidad absoluta de mi vida, verdad completa demasiado densa para mi inteligencia y fin de mis fines.

Como decía maravillosamente Simone Weil, es tal la certeza de que no existe en ningún lugar del mundo el bien perfecto, que significa que existe fuera del mundo y que tiene en un rincón de mínima extensión de nosotros mismos su cómplice, su hechura dentro del propio mundo que tanto lo desconoce. 
Los horizontes existenciales que se abren ante quien reconoce estas situaciones y estas verdades esenciales de ninguna manera, como podría quizá parecer a una mirada apresurada y superficial, son solitarios y ajenos a toda comunidad. Para señalarlo, me he permitido hace un momento elevar a la jerarquía de virtud teologal la forma máxima de la misericordia, por si alguien pasa por alto que la caridad teologal posee indudablemente esta dimensión. Y quizá fuera más claro hablar en el mismo sentido de compasión o de solidaridad, elevando así, por cierto, a la dignidad que merece este último concepto de hasta ahora tan vagos perfiles en la filosofía y la teología. Lo que la noción de solidaridad contiene fue también descrito de manera magistral por Unamuno, cuando se atrevió a afirmar que sólo ha aprendido el concepto de Dios un hombre que se haya compadecido hasta de la más lejana partecita de realidad que haya en el mundo: la estrella más remota, por ejemplo, o el menor de los pobres de Dios. El doloroso gozo de existir en riesgo, pendientes constantemente del compromiso para con la verdad, a cuya fe nos debemos so pena de malograr por completo la vida y contribuir en lo posible a malograr las vidas de los que nos rodean amorosamente, no nos abre tan sólo a la alteridad transcendente e hiperbólica de Dios, sino a las alteridades, a las individualidades precarias, de todos los demás hombres y, en última instancia, como han querido los mejores románticos, de todas las demás criaturas. Este mismo anhelo quebradizo que soy yo lo es también cualquiera cerca de mí que posea conciencia, y sin el fruto del amor entre los hombres careceríamos de las gradas que permiten la subida al monte de Dios. Ya Platón había entendido que Belleza es el nombre apropiado para la fascinación absoluta del Misterio divino, del Bien perfecto y transcendente; y que la belleza es la generosidad de que el bien aparezca representado en bienes imperfectos, donde se reflejan también nuestras carencias, pero que prometen -y entregan-, como consecuencia de la unión entre ellos y nosotros, no una suma sino una multiplicación de las respectivas riquezas.

Sin compasión profunda, sin amor real a los bienes precarios con los que compartimos vida y destino, no hay auténtica experiencia de la profundidad de la existencia, es decir, no hay amor a Dios ni hay esperanza absoluta ni se confía por entero en la realidad creada, sino que las virtudes teologales son suplantadas por unos remedos suyos con los que podemos quedar mortalmente conformes. 


\section{$\S 4$ Fidelidad, compromiso, arrepentimiento y sus contrarios}

Todas las personas traen escrito en la frente, como decía la misma Simone Weil, el mandamiento básico: No me dañes, que mejor sería traducir en positivo: Ámame; dame testimonio creíble de que vives de la esperanza absoluta, de que no te has olvidado de Dios.

Por las más hondas razones antropológicas, es cierto que, empezando por ser la búsqueda de la verdad un compromiso individual de por vida, la búsqueda de la salvación, en la plenitud de su sentido, es de por vida un compromiso social, comunitario. El mismo Sócrates, que podría haber reservado para sí su saber, dio un paso mucho más allá de lo que le exigía el oráculo délfico y trató de demostrar a sus prójimos, en la mayor medida posible, que cuando la existencia se vive superficialmente, sin preguntas radicales, sin anhelo insaciable, es porque se funda en convicciones de tan malas raíces como la casa con los cimientos enterrados en la arena a orillas de una rambla. Y esta compasión suya lo llevó a la muerte, como al boddhisattva lo retiene entre los sufrimientos del mundo la necesidad de consolarlos todos antes de poder dejarse llevar a consumar la dicha por medio de la extinción del tiempo que conoce la muerte.

Kierkegaard reconoció que, sin embargo de nacer la existencia del modo que he tratado de evocar describiendo la que he llamado experiencia matriz, puede disolverse el significado profundo de los descubrimientos incipientes de la infancia en modos de vida que olviden precisamente la irreversible seriedad del paso del tiempo. Como en una recuperación de la edad de los juegos, el hombre joven puede dejarse llevar por la belleza creada hasta el límite de desatender por entero el sentido ascensional, en la dirección del bien transcendente, que de por sí debe tener el amor. En vez de subir hacia la unidad, persiste Don Juan en la simple variedad infinita de todas las realidades placenteras, marginando toda memoria de la muerte y, por ello, todo pensamiento propiamente moral. Sólo disfrutar de la efímera flor de las cosas posee para este modo de vida plena significación, y tanto más se goza del mundo cuanto más se recorren sus enigmas y más culto se es. La existencia estética, conforme al nombre que Kierkegaard le da, amplía sus horizontes dedicándose a pensar todas las ideas, imitando, pues, la sabiduría auténtica: convirtiéndolo todo en pura aventura, pura cacería.

No se debe creer ni por un momento que se es un hombre moral o un hombre religioso porque se tiene en la cabeza pensamientos profundos, 
porque se ha leído mucho, porque nos hemos sentado a los pies de grandes maestros. Estéticamente se puede alguien casar, como se puede dedicar a vivir entre los pobres con voto religioso. Nada externo revela en qué estadio existencial se vive. El síntoma es sólo íntimo, y consiste en que para el estadio del juego, no hay nada que deje de ser posible por el hecho de que se haya optado antes por algo. En otras palabras, el estadio en el que sólo se juega y se goza de la belleza imperfecta de las cosas, es aquel en el que, aunque el propio sujeto crea a veces lo contrario, no existen decisiones auténticas, o sea, pasos, saltos existenciales, de los que no es posible volverse atrás. Por esto se puede decir que el que no ha salido de este modo de la vida nunca se ha resuelto definitivamente por nada. No ha vivido sino que sólo ha hecho experiencias, tanteos. Ha sobrevolado posibilidades, pero nunca nada ha sido para él de veras posible y luego real e irrevocable por haberse decidido en su favor.

Está en este estadio aquel hombre para el que todo paso que piensa haber dado puede en seguida, a voluntad, cuando el placer así se lo pida, ser también retirado. Don Juan ni siquiera posee el sentido duro y trágico de la traición, por más que sus víctimas lloren ante él. Piensa a lo sumo que echan de menos estúpidamente la cima del placer, que ya se sabe que es única y pasajera, que sólo se repite de alguna manera cuando cambiamos el objeto del gozo. Don Juan asume que sus amantes abandonadas simplemente no aman tanto, tan intensamente, como él, y que aún les queda mucho que aprender en la escuela de la vida estética.

Lo tremendo de esta descripción es la verdad de que se puede, en efecto, vivir como si no se hubiera vivido: sin haberse introducido de verdad en ninguno de los caminos de la existencia. Cabe ser superficial hasta el extremo de borrar todos los efectos de la experiencia con la que se abrió un día nuestra vida real.

Sólo existe aquel para quien hay dadas ciertas posibilidades y la necesidad de optar entre ellas, o sea, de realizar irreversiblemente alguna convirtiéndose él mismo en lo que ella es. Una vez que esta transformación real de la existencia se ha producido, nuevas posibilidades, antes impensadas, se abren ahora, mientras que las antiguas se cierran para siempre, dejan de ser posibles.

No hace falta siquiera subrayar que existe algo así como un compromiso serio consigo mismo -después corregiré este modo de hablar muy imperfecto-: simplemente ocurre que el que existe está introducido en un 
viaje auténtico, semejante a la ruta marina sin hitos previos, donde la detención es ya también un modo de avance, aunque pueda serlo hacia el fracaso y la desesperación.

No existir es, en cambio, mirar como un espectador el primer círculo de posibilidades, que realmente no se tienen porque se ha optado por la actitud de no optar por nada. Y uno cree ilusamente que podrá conocer mejor el mundo sin comprometerse con nada, sólo ampliando las vistas desde su atalaya por cualquier medio, entre los que destaca, desde luego, el refinamiento cultural. San Agustín se refería con una frase terrible a estos hombres -todos lo somos o lo hemos sido alguna vez, seguramenteque, por nada más que mirar y lamer imágenes, creen que están saciando con seres de bulto, de carne, su hambre. No hincan a nada el diente; para ellos no existe el tiempo todavía; no tienen sentido propiamente dicho del bien y del mal; ni siquiera pecan, de tan poco como viven; lo más que les sucede es que lamentan su incapacidad de imitar de veras a Don Juan, porque este prototipo sólo existe en el teatro, pero en la realidad no hay vigor como el suyo, no hay alegría despreocupada como la suya, y las mismas conquistas estéticas y donjuanescas dan mucho trabajo, terminan con penas y dejan un gusto de amargura sobre cuyas virtudes curativas y providenciales el mismo Agustín es elocuente hasta la exageración.

Kierkegaard ha visto los abismos de una vida para la que ningún fracaso erótico -en el amplísimo sentido que podemos dar a esta palabra, traducción de la agustiniana libido- trae de suyo un punto final. Cabe no despertarse jamás. Y los caminos del despertar son secretos, más aún que difíciles; están a nuestro alcance en todo momento, pero precisan de un ímpetu que tiene que venir, al parecer, como un socorro para el que no bastan nuestras fuerzas ni tampoco el golpe que nos dé ningún amigo bienintencionado. Sócrates creyó demasiado en los beneficios del diálogo. Hablar de temas profundos o trágicos, aunque sea hablar de esto mismo que ahora nos ocupa, no mueve, en principio, a nadie más que estéticamente. El secreto de la intimidad se lleva consigo la clave por la que cada hombre puede o no puede saltar más adelante. Y sin embargo, el que ha saltado y es consciente de que ha logrado transformar su existencia, desde luego que estará siempre lleno de palabras y recursos con los que procurar el socorro de las personas queridas a las que ve quedarse del otro lado del abismo. El hombre que vive ética o religiosamente aspira a que Sócrates tenga razón, en el fondo, y sea posible convencer con las palabras, con 
el ejemplo, con el testimonio de las obras, con los beneficios del amor y, en definitiva, haciéndose todo para todos con tal de ganarlos a todos.

Existen formas innumerables del amor, de entre las que el pensamiento occidental parece apenas haber entresacado unas pocas. Sigue pendiente una fenomenología más arriesgada y completa de este género sobreabundante de la forma central de la vida. Sólo explorando la auténtica variedad de tales fenómenos se podrá en el futuro alcanzar, al mismo tiempo que las bases de una doctrina espiritual renovada sobre la mística vivida comunitariamente -y en especial, dentro de la existencia familiar-, también una mirada más honda y completa sobre las maneras de enlazar la vida personal a la vida de los grupos humanos a los que se sirve.

En esta misma dirección, Rosenzweig y Levinas, los más interesantes pensadores judíos del siglo recién pasado, han propuesto una teoría de la praxis religiosa que entiende como gracia fundamental en la existencia de cada hombre la simple presencia del prójimo junto a nosotros. Según sus descripciones, la vida humana, más todavía que ser-en-el-mundo, es sercon-el-otro-y-los-otros. Levinas ha llegado a escribir que el tiempo mismo propiamente no transcurre -lo que equivale a afirmar que para el hombre no se abren posibilidades que de veras lo sean y ya no regresen una segunda vez- más que a partir del momento en que a una vida se le presenta la alteridad profunda de otra vida. No ha puesto Levinas el acento tanto en los esfuerzos, los méritos y los trabajos que supone la conquista de esta alteridad, al revés que como hizo Kierkegaard, pero le otorga un papel del todo fundamental en cualquier toma de conciencia verdaderamente humana de la vida.

Sea como quiera, y sobre todo es gracia primordial de Dios y hasta revelación suya primordial, una mismidad que tiene noticia inolvidable de una alteridad queda, ya sólo por esto, introducida para siempre en la historia, en el pasar del tiempo, en el compromiso gravísimo de la responsabilidad moral.

El mandamiento sencillo y solemne de respetar como cosa santa la alteridad del otro hombre liga, en este sentido, a una radical fidelidad cuyo abandono no sólo será una traición moral sino el retroceso a un estado de barbarie prehumano. Da lo mismo que haya, tristemente, que comprender la historia y la política del mundo en términos en los que esta barbarie prehumana es el rasgo sobresaliente. A nuestra vida sólo le da sentido, sólo la orienta, no su soledad sino, al contrario, su definitiva perturbación por 
el hecho de que hay ante ella otro, otros, a los que se debe servir incondicionalmente, como un rehén, sin calcular antes la manera en que se nos devolverán los intereses y productos de nuestra entrega.

De acuerdo con estos pensadores del judaísmo, el quebrantamiento básico de la ley de Dios consiste en la negación práctica de la real alteridad de los otros; en tomarlos, en última instancia, como si fueran partes de nosotros mismos, o como si ellos y yo, al mismo tiempo, nos integráramos en una totalidad donde las diferencias respectivas se anularan. En todos estos casos, el deber incondicional de servicio al otro se somete a determinadas mediaciones, aparentemente muy sensatas, que, en realidad, sólo conducen a ponerlo en duda, lo que ya de suyo equivale a suspenderlo y a destruir, por lo mismo, su esencia de orden incondicional, o sea, absoluta, o sea, divina.

Y es que pensar demasiado en sí mismo es exactamente lo opuesto a pensar; ya de entrada, porque es una actividad de alejamiento de los deberes que tiende a crear en el espacio estrechísimo de la propia subjetividad un gran hueco irreal. Pensar profunda y largamente en el sentido de la existencia, las cosas y las otras personas, es un movimiento contrario al ilusorio pensar en y sobre sí mismo; y además, es cosa que sólo se realiza al calor y a la luz de la fidelidad para con los deberes ya siempre contraídos con los demás por el mero hecho de su presencia junto a nosotros como auténticas alteridades: como tú y él y ella, no como otro yo. Lejos de ser el pensamiento y la acción magnitudes que se contrarrestan, según solemos imaginarlas, colaboran a la misma tarea porque efectivamente son las dos caras de la misma realidad.

La fidelidad no es para consigo mismo, sino para con el sentido profundo, la verdad de la situación existencial de las profundidades, al mismo tiempo que para con los otros. El famoso fuero interno no es más que el escenario donde las voces de la existencia en comunidad se dejan oír. El destino personal es la prolongada confianza en que no se debe ni se puede hacer otra cosa que afrontar la verdad y cumplir con el mandamiento, o sea, tratar de seguir recibiendo la gracia de una esperanza absoluta. Y la esperanza jamás tiene esta calidad perfecta cuando sólo contempla a un sujeto aislado dentro de su horizonte de futuro. Este futuro de la esperanza absoluta no es el mío, sino el futuro de Dios, donde toda la realidad cabrá, y el presunto justo solitario habrá de pasar por el trance de hallarse sentado a la misma mesa de banquete que el pordiosero que le parecía indigno un rato antes, cuando se tropezó con él en el camino. 
Naturalmente que el arrepentimiento y la enmienda del rumbo de la vida son fenómenos de radical legitimidad tanto moral como religiosa. Compromiso y fidelidad, precisamente, sólo se pueden tener y guardar respecto de los factores que aparecen en la situación de profundidad existencial: la verdad y los otros; no cabe fidelidad a las cosas o a las instituciones en tanto que tales, como tampoco existe en realidad la fidelidad a sí mismo, de la que tanta propaganda se hace todavía. Estas expresiones, que creo muy peligrosas -y que culminan en aquella otra, según la cual lo más difícil es perdonarse uno a sí mismo, cuando semejante fenómeno ni siquiera es posible-, confunden el carácter individual de la existencia, siempre movida hacia lo otro divino a través de los otros finitos, con una concepción de ella de índole material, donde sujeto quiere decir una cosa bien repleta de necesidades que hay que atender antes de mirar en la dirección de alteridad ninguna. Como sostenía la espléndida imagen conceptual de los metafísicos medievales, la verdad es que el pensamiento eterno que nos ha concebido a cada uno antes de querernos existentes en el mundo, constituye de suyo originalmente no una pluralidad incontable de ideas, una para cada individuo real, sino, al contrario, una única inteligencia que se conoce a sí misma con plenitud, de modo que las ideas sólo son la expresión ad extra de la riqueza insondable del Verbo de Dios. Ser radicalmente un individuo es lo contrario de ser una totalidad solitaria y autosuficiente. No tener especie propiamente dicha se opone, pese a las apariencias, a bastarse a sí mismo.

Pero esta condición moral y religiosa de la humanidad sólo se abre al pensamiento y a la acción cuando se logra dejar definitivamente atrás el predominio del juego y el gozo que caracterizan la existencia en su modo estético. No que la pasión se abandone como cosa abominable, sino que se la sobreeleva hasta que llega al rango de pasión infinita. Y yo mismo, por cierto, no puedo ser para mí el objeto de mi pasión infinita.

Las argucias del autoengaño son tantas como las arenas del mar. No se trata principalmente de receta alguna, pero sí se deberá recordar, como quien invoca aquello que solamente puede ser la señal que discierna en las horas oscuras, que la esperanza absoluta discrimina qué es fidelidad y qué no lo es, qué es arrepentimiento y qué es lo contrario del arrepentimiento, aunque venga vestido con sus galas. 